\title{
Análise pelo Modelo de Rasch do Ditado ADAPE: Considerações da Ortografia
}

\author{
Susana Gakyia Caliatto \\ Débora Cecílio Fernandes \\ Universidade do Vale do Sapucaí \\ Pouso Alegre, MG, Brasil
}

\begin{abstract}
RESUMO
Este estudo teve como objetivo identificar as palavras com maior dificuldade de escrita, com base na análise pelo modelo de Rasch, e indicar a composição das palavras do ditado ADAPE que produzem mais erros. Participaram 221 estudantes, com idades compreendidas entre 6 e 11 anos, do segundo ao quinto ano de uma escola particular do estado de Minas Gerais. A média da dificuldade dos itens foi estabelecida convencionalmente como zero. Os resultados indicaram que a palavra Cássio foi a mais difícil. Outras sete palavras também foram muito difíceis. Mostrou-se que o ditado contém palavras que exigem diferentes conhecimentos ortográficos, o que permite avaliar os estudantes em distintas etapas da alfabetização. As palavras foram discutidas em função de categorias de erros da língua portuguesa.
\end{abstract}

Palavras-chave: Escrita; ortografia; teoria de resposta ao item.

\section{ABSTRACT \\ Analysis by Rasch Model of ADAPE Dictation: Considerations from Orthography}

This study aimed to identify the most difficult words, based on the Rasch model analysis, and indicate specific word compositions from the ADAPE dictation that produce more errors. Participants were 221 students, aged between 6 and 11 years, from the second to fifth grade of a private school in the State of Minas Gerais. The mean item difficulty was conventionally established as zero. Results indicated that the most difficult word was Cássio. Other seven words were also very difficult. It was shown that the dictation contains words that require different orthographic knowledge, which allows the assessment of students in different literacy stages. The words were discussed according to Portuguese language error categories.

Keywords: Handwriting; orthography; item response theory.

\section{RESUMEN}

\section{Análisis por el Modelo de Rasch del Dictado ADAPE: Consideraciones de la Ortografia}

Este estudio tuvo el objetivo de identificar las palabras con mayor dificultad de escritura, basándose en el análisis por el modelo de Rasch, e indicar la composición de las palabras del dictado ADAPE que producen más errores. Participaron 221 estudiantes, con edades comprendidas entre 6 y 11 años, del segundo al quinto curso de una escuela privada del Estado de Minas Gerais. Los resultados indicaron que la palabra Cássio fue la más difícil. Siete otras palabras también fueron muy difíciles. Se mostró que el dictado contiene palabras que requieren diferentes conocimientos ortográficos, lo que permite evaluar los estudiantes en diferentes etapas de alfabetización. La dificultad de las palabras se discutió en función de categorías de errores de la lengua portuguesa.

Palabras clave: Escritura manual; ortografía; teoría de respuesta al ítem. 


\section{INTRODUÇÃO}

A leitura e a escrita se desenvolvem por meio de processos mentais bastante complexos e são estudados por diferentes abordagens. Os estudos progridem na direção de compreender seu funcionamento devido ao fato de que esta aquisição é uma necessidade fundamental para alcance de novos conhecimentos, principalmente os escolares (Kessler \& Treiman, 2013).

De acordo com a literatura, a leitura e a escrita sob aspectos psicossociais são tidas como ferramenta para o processo evolutivo de novas aprendizagens sociais, de comunicação, de relações interpessoais e profissionais. Pela valoração social da escrita, a sua obtenção resulta em influência para a autoestima, autoconceito e motivação pessoal e atua como um favorecedor de novas aquisições em diferentes esferas da vida (Sisto \& Martinelli, 2008).

$\mathrm{Na}$ perspectiva psicolinguística que aborda aspectos internos da linguagem, estuda-se a habilidade de refletir e manipular intencionalmente a língua como objeto do pensamento, derivando a habilidade metalinguística. Compreende-se que há diferentes medidas de consciência metalinguística que ajudam a construção de conhecimentos sobre aspectos normativos da língua sendo que tais habilidades dependeriam de aprendizagens explícitas para serem desenvolvidas (Urquijo, 2009; Bublitz, 2010; Mota, et al., 2011). Compreende-se ainda que as habilidades metalinguísticas, que compõe a aprendizagem da leitura e escrita são a consciência fonológica (Urquijo, 2009), a consciência sintática (Bublitz, 2010), a consciência morfológica (Mota, et al., 2011) e a consciência lexical (Campos, Pinheiro, \& Guimarães, 2012).

A consciência fonológica se refere à habilidade para analisar a linguagem oral de acordo com suas unidades sonoras constituintes, tais como as sílabas e rimas ou ainda a habilidade de refletir sobre os sons que compõem a fala (Urquijo, 2009). Manzano, et al. (2008) abordam que a consciência fonológica incide com o avanço na aquisição da leitura e da escrita, conforme a habilidade de perceber que duas palavras rimam e apresentam semelhanças ortográficas na escrita. A percepção dessas rimas e aliterações permite verificar semelhanças ortográficas e estabelecimento de conexões entre padrões ortográficos e os sons das palavras.

Quando se escreve ortograficamente refletindo-se sobre as menores unidades linguísticas com significado próprio, dá-se conta da estrutura morfológica de cada palavra ou concebe-se a habilidade de consciência morfológica da escrita. A representação ortográfica mental da palavra requer ainda a seleção dos grafemas e o tipo de letra a ser empregada (maiúscula, minúscula) e o os aspectos motores para executar os movimentos correspondentes a cada grafema (Manzano, et al. 2008). Campos, et al. (2012) descrevem que a consciência lexical diz respeito à habilidade para segmentar a linguagem oral em palavras de forma sistemática, considerando o significado independente do contexto como os substantivos, adjetivos, verbos e demais classes gramaticais com significados próprios e, independente de palavras que adquirem significado apenas no interior de sentenças como os conectivos ou conjunções, preposições, artigos. Como as habilidades metalinguísticas são aprendizagens conscientes, considera-se que os erros de escrita possam ser amenizados ou evitados a partir da prevenção ou identificação de dificuldades recorrentes da língua escrita.

As avaliações da aquisição e do funcionamento da escrita ocorrem também por meio da apreciação dos erros da escrita de palavras e frases. Diferentes perspectivas teóricas tratam da análise dos erros da escrita e sugerem que os estudos podem apontar algumas influências e motivações para que os mesmos ocorram e, em consequência disto, concebem também as dificuldades de aquisição da língua escrita (Mota,, et al. 2011; Zorzi \& Ciasca, 2009).

Considerando estudos de tipos de erro na escrita divulgados na literatura Caliatto e Martinelli (2005) desenvolveram três categorias de erros de escrita. A primeira delas se refere aos erros provocados pelo apoio na linguagem oral devido às relações existentes entre letras e sons. Neste caso, os erros incluem trocas entre letras, omissões ou acréscimos, mas, normalmente, essas palavras podem ser lidas, porque preservam a sonoridade quase perfeita de acordo com a palavra escrita ortograficamente e compreende-se o seu significado mesmo que a palavra esteja isolada, fora de um texto.

Essa categoria foi subdividida em quatro subgrupos, levando em consideração algumas especificidades. O primeiro subgrupo inclui o emprego das consoantes e dígrafos, que pode gerar vários tipos de erros. São exemplos de erros fiseram/fizeram. (Caliatto \& Martinelli, 2005). As consoantes que representam fonemas surdos/sonoros, que sonoramente são próximas, causam dúvidas ao serem escritas e constituem as trocas entre as consoantes: $\mathrm{p}$ e b; $\mathrm{t}$ e $\mathrm{d} ; \mathrm{q}$ e $\mathrm{c} / \mathrm{g}$; f e v; z e s/c/ç; j e ch/j. São exemplos desse tipo de erro, princar/brincar. Ainda na mesma classificação de erros, pode-se encontrar dificuldades no uso da letra $\mathrm{h}$ no início de palavras, pois esta letra não representa nenhum som e seu uso é arbitrário. São exemplos, hontem/ontem. 
As omissões de consoantes $r$ e $s$ no final de palavras como passa/passar; todo/todos, também foram categorizadas, uma vez que são omissões que ainda permitem a leitura da palavra e que muitas vezes representam a fala regional dos seus autores. Da mesma forma ocorrem as trocas entre consoantes $1 / \mathrm{r}$ como em vortar/ voltar (Caliatto \& Martinelli, 2005).

Ao conceber a escrita como uma relação entre letras e sons, o aluno, na sua forma coerente de supor a ortografia das palavras, pode empregar incorretamente as vogais, representando diretamente o som de sua fala. Pode-se encontrar escritas trocadas como tardi/tarde; e omissões e acréscimos como, por exemplo, chego, no lugar de chegou ou feiz em vez de fez.

O emprego das formas que representam o som nasal, segundo Morais (2007), constitui uma grande fonte de dificuldade para quem aprende a escrever, porque, no português, existem vários modos de representá-los como usando o "m" ou o " $\mathrm{n}$ " em final de sílaba (bambu e banda), usando o til (manhã), usando o dígrafo nh (minha, galinha) ou por contiguidade, no qual a sílaba seguinte inicia com a consoante, como é o caso de cama, cana, banana. Destaca-se o problema da nasalização das sílabas am e ao, cujo exemplo é beberam/ beberão (Caliatto \& Martinelli, 2005).

Existem ainda na primeira categorização os tipos de erro que dizem respeito a segmentação indevida das palavras. Isso ocorre porque a forma oral não permite, muitas vezes, evidenciar onde começa e onde termina uma palavra numa sentença que foi dita. Isso pode causar erros na escrita dos alunos, que podem escrever "deverão" no lugar de "de verão". Numa segunda categoria de análise de erros da escrita há erros devido aos aspectos visuais ou gráficos. Erros desta natureza são aqueles que apresentam trocas, omissões, acréscimos ou inversões de letras que deformam a leitura da palavra, porém os seus produtores não percebem tais modificações e consideram a escrita correta. Não se nota apoio na oralidade, mas que provavelmente seu aspecto visual satisfez o produtor da escrita. Exemplo astras/atrás; visiho/visinho.

Inclui-se também o emprego de letras com formato semelhante em que o aluno considera aspectos da forma visual das letras e dígrafos apoia-se mais na memória visual do que na sonoridade das letras. $\mathrm{O}$ apoio visual não confere à escrita precisão sonora. Neste tipo de erro a palavra parece visualmente com a escrita padrão, como em vernelho/vermelho. O último grupo de tipos de erros levantados por Caliatto e Martinelli (2005) prevê erros de escritas particulares em que os escritores ainda comentem erros que as tornam ilegíveis mediante a escrita padronizada. Caso em que foi ditada a palavra "Adão" e o escritor concebeu "Adre". Enfim, todos esses tipos de erros podem se manifestar na escrita das crianças. Contudo, para a escrita correta, as crianças devem fazer uso das estratégias metalinguísticas, adquirir adequadamente o conhecimento ortográfico e suas regras e aprender a aplicá-lo.

Para a avaliação e o ensino da ortografia, a atividade de ditado é comumente escolhida nas escolas. A pesquisa científica contempla o estudo de avaliações de aprendizagem da escrita por meio desta ferramenta (Caliatto \& Martinelli, 2008; Mota, et al. 2011; Paolucci \& Ávila, 2009). Para contento do uso do ditado no ensino da escrita, bem como na sua avaliação, é necessário que o instrumento suscite do escritor boas reflexões a respeito da escrita.

Um instrumento de avaliação da escrita, validado para este fim, é a Avaliação de Dificuldades na Aprendizagem da Escrita - ADAPE (Sisto, 2001). Foi criado considerando um levantamento de palavras encontradas em materiais didáticos de alfabetização, das quais crianças das séries iniciais erravam com mais frequência. Para buscar evidências de validade do instrumento, Sisto (2001) comparou o desempenho em escrita de três grupos, quais sejam, grupo 1 (critério), formado por crianças do final de primeira serie, já alfabetizadas, grupo 2, formado por crianças de primeira série em fases heterogêneas de alfabetização e grupo 3, constituído por crianças de segunda série. Foi observado que o ADAPE mostrou uma tendência a discriminar nitidamente os três grupos e que as diferenças encontradas entre os grupos foram as esperadas. Esse resultado foi interpretado como evidência de validade. $\mathrm{O}$ autor apresentou também diferentes medidas de precisão do instrumento, por exemplo, os valores de alfa obtidos para os três grupos e para a amostra geral variaram de 0,89 a 0,98 .

Com estes dados pode-se inferir que o ADAPE apresentou boas condições para sua utilização em identificar dificuldades específicas na ortografia da Língua Portuguesa escrita no Brasil, além de revelar o nível de dificuldade de aprendizagem em escrita e a possibilidade de comparação entre os pares (Sisto, 2001). Após as análises iniciais, o instrumento não sofreu outras análises psicométricas de seus itens, nem pela teoria clássica dos testes e nem pela Teoria de Resposta ao Item (TRI). Apesar de que este instrumento vem sendo usado largamente em pesquisas de verificação da aprendizagem da escrita (Caliatto \& Martinelli, 2005).

Ainda descrevendo o instrumento, sabe-se que consiste de um ditado, constituído por 114 palavras no total e em que 60 apresentam algum tipo de dificuldade classificada em quatro tipos: encontro consonantal, 
"tarde"; dígrafo; sílaba composta: "quente"; e, com sílaba complexa, que se refere às palavras que podem ser escritas de diferentes maneiras, apoiando-se na fala, como por exemplo, "casa/caza". Dessa forma, o instrumento considera tanto as representações fonológicas, como prevê as arbitrariedades do complexo sistema de escrita, uma vez que a relação fonemagrafema não é suficiente para compor uma escrita ortográfica, que depende do emprego de regularidades contextuais e irregularidades da escrita expressas nas convenções ortográficas. Ainda conforme previsto por este instrumento, a dificuldade em empregar corretamente as letras e símbolos gráficos (acentuação e aplicação da letra maiúscula e minúscula) provoca os erros de escrita. Assim, a estrutura das palavras pode favorecer a manifestação de alguns tipos de erros e a constituição de algumas palavras deve torná-las mais difíceis do que outras. Os estudos relacionados às principais dificuldades de escrita na Língua Portuguesa no Brasil, considerando tipos de erros, corroboram com resultados encontrados no estudo do ADAPE (Cagliari, 2006; Morais, 2007; Zorzi \& Ciasca 2009) o que leva a hipotetizar que as dificuldades apontadas são comuns na aquisição da escrita.

Em consonância com este instrumento de avaliação da escrita, concebe-se a importância de um levantamento da escrita de grupos de escolares a fim de identificar os principais erros apontados nas escritas destas crianças, considerando as dificuldades da língua para conhecer e apontar possíveis intervenções para o bom desempenho da escrita de alunos nas séries iniciais do Ensino Fundamental. Para tanto, o presente estudo teve como objetivo identificar as palavras com maior dificuldade de escrita, a partir da análise pelo modelo de Rasch, apontando as dificuldades específicas da composição das palavras do ditado ADAPE.

\section{MÉTODO}

\section{Participantes}

Participaram 221 estudantes matriculados no segundo ao quinto ano de uma escola particular do interior do estado de Minas Gerais, com idades compreendidas entre 6 e 11 anos. A média de idade dos participantes foi de $8,33(\mathrm{DP}=1,16)$. Do total de crianças, 105 eram do sexo masculino e 116 do sexo feminino. Em relação ao ano escolar, 42 crianças frequentavam o $2^{\circ}$ ano, 63 cursavam o $3^{\circ}$ ano, 59 o $4^{\circ}$ ano e 57 cursavam o $5^{\mathrm{O}}$ ano.

\section{Instrumento}

Foi utilizado o instrumento de Avaliação de Dificuldades na Aprendizagem da Escrita - ADAPE
(Sisto, 2001), destinado à avaliação da escrita ortográfica da Língua Portuguesa, que consiste em um ditado com o título de "Uma tarde no campo", constituído por 114 palavras, sendo que 60 apresentam algum tipo de dificuldade de escrita (encontro consonantal, dígrafo, sílaba composta e sílaba complexa). As outras 54 não são consideradas como palavras com dificuldade e são exemplos: dia, médico, um, entre outras.

Para correção do instrumento, cada uma das palavras deve ser escrita corretamente, considerando omissões, acréscimos, emprego das letras maiúsculas e acentos. Para fins de correção da escrita da palavra considerou-se apenas acerto (escrita totalmente correta) e erro (independentemente da quantidade de erros na mesma palavra).

\section{Procedimentos}

Inicialmente o projeto foi submetido e aprovado pelo CEP, sob protocolo (1775/2011) e os responsáveis pelos participantes assinaram Termo de Consentimento Livre e Esclarecido. As aplicações do ditado ADAPE foram realizadas coletivamente em sala de aula junto à apreciação dos professores da turma e cada aplicação durou aproximadamente 30 minutos. Cada palavra foi lida apenas uma vez para as crianças.

\section{Análise de dados}

Para a análise dos dados, foi utilizado o software Winsteps versão 3.70.0.4 (Linacre, 2009). Esse software é usado especificamente para realizar análises do modelo de Rasch (Rasch, 1960).

\section{Modelo de Rasch}

Trata-se de um modelo probabilístico que estima o nível de dificuldade dos itens e de habilidade dos sujeitos separada e independentemente. Não obstante, para isso é necessário que haja um ajuste dos dados empíricos ao modelo de Rasch (Rasch, 1960). Uma das características fundamentais do modelo é a premissa de que o comportamento de um sujeito ante um item pode ser explicado pelo traço ou habilidade latente $(\theta)$, não observável, de modo que essa variável latente influi sobre a probabilidade de acertar um item (Embretson \& Hershberger, 1999). As respostas aos itens são variáveis observáveis que são influenciadas pelos traços latentes e nesse sentido cada pessoa possui certa quantidade de traço $(\theta)$ e cada item requer uma quantidade determinada de traço para ser acertado.

Assim, o modelo de Rasch determina que a probabilidade de acertar um item depende da diferença entre o nível de traço da pessoa em determinado 
construto (habilidade em escrita) e a dificuldade do item (quantidade de traço necessária para a resolução do item, representada por $\beta$ ). A fórmula da probabilidade de acerto do modelo de Rasch é uma função logarítmica: $\mathrm{P}_{\text {is }}=\mathrm{e}^{(\theta s-\beta i)} / 1+\mathrm{e}^{(\theta s-\beta i)}$

Onde $e$ é a base dos algoritmos naturais $(2,7183)$, $\theta$ s é o nível de traço da pessoa e $\beta$ i é o nível de dificuldade do item. Observa-se que os únicos valores que afetam a probabilidade são os de $\theta$ e $\beta$. A estimação dos parâmetros foi realizada pelo procedimento de Máxima Verossimilhança (Linacre, 2009), que parte das respostas reais dos sujeitos aos itens e faz uma estimação simultânea de ambos os parâmetros. Os níveis de habilidade dos sujeitos são estimados inicialmente, considerado qual o nível mais provável que explique as respostas das pessoas, em função da dificuldade dos itens. Posteriormente, repete-se esse processo de busca para averiguar os valores de dificuldade dos itens que maximizam a probabilidade das respostas observadas. Para esse procedimento, a média da dificuldade dos itens é convencionalmente estabelecido como zero.

Para o uso do modelo de Rasch é necessário que os dados obtidos empiricamente se ajustem ao modelo. $\mathrm{O}$ ajuste indica que os participantes responderam conforme a expectativa do modelo, quer dizer, uma criança com pouca habilidade de escrita apresenta uma baixa probabilidade de escrever uma palavra difícil, enquanto que uma criança que escreve muito bem apresenta uma probabilidade maior de acerto da mesma palavra difícil. Igualmente, uma criança pouco hábil em escrita deve ser capaz de escrever uma palavra fácil, assim como uma criança muito hábil.

Esse ajuste ou desajuste dos dados é obtido pelos índices de infit e outfit dos participantes e dos itens e revelam se há uma maior ou menor variação no padrão observado de respostas dos sujeitos e no padrão esperado de respostas. Os valores de infit e outfit são a média das diferenças entre as respostas observadas e as esperadas. Como critério de aceitação desses índices, foram utilizados os de Linacre (2002). O autor considera que os valores entre 0,5 e 1,5 revelam divergências pouco relevantes. Os valores de 1,5 a 2,0, a sua vez, indicam que as divergências são moderadas, mas não degradam as medidas, enquanto que os valores superiores a 2,0 distorcem a medida e são considerados aberrantes. Valores inferiores a 0,5 manifestam sobreajuste (maior ajuste do esperado, mas ao acaso) e são menos produtivos, mas não chegam a ser degradantes. Além disso, os desajustes em relação ao outfit não são tão problemáticos como o desajuste do infit. Ressal- ta-se que até $15 \%$ de desajuste de pessoas ou itens é considerado adequado.

\section{RESULTADOS}

A Tabela 1, adiante, mostra o resumo dos parâmetros das crianças, a média, os valores máximo e mínimo da pontuação, da medida de Rasch, do erro de medida, infit e outfit. Apresenta ainda, os valores do Person Reliability Index e do alfa de Cronbach, que são indicadores de fidedignidade das respostas das crianças.

$\mathrm{O}$ valor do Índice de Fidedignidade dos Participantes (Person Reliability Index) foi 0,96 e o do alfa de Cronbach foi 0,98 , considerados adequados. A pontuação total média das crianças foi de $84(\mathrm{DP}=23,7)$ acertos, com mínimo de 1 e máximo de 113 pontos. A média da medida de Rasch foi $1,74(\mathrm{DP}=1,79)$ logits, a criança com maior nível de habilidade apresentou uma medida de 6,18 logits e o participante menos hábil obteve $-5,62$ logits. O erro de medida foi, em média, 0,33 ( $\mathrm{DP}=0,13)$, com valor máximo de $1,04 \mathrm{e}$ mínimo de 0,22 . Os valores médios de ajuste foram adequados, a média do infit foi $0,98(\mathrm{DP}=0,18)$, com valor mínimo de 0,61 e máximo de 1,62 , enquanto que a média do outfit foi 1,13 ( $\mathrm{DP}=1,01)$, com máximo de 9,90 e mínimo de 0,04 . O valor máximo de outfit indica um desajuste muito alto, quer dizer, essa criança não respondeu da forma esperada pelo modelo de Rasch.

Como a média do outfit ficou próxima de 1 , esse caso aberrante de desajuste parece ter sido isolado. Para averiguar a adequação das crianças de forma mais precisa, calculou-se a porcentagem de participantes que não responderam de acordo com o previsto pelo modelo. Em relação ao infit, das 221 crianças apenas duas $(0,9 \%)$ desajustaram moderadamente e nenhuma apresentou desajuste severo. No que diz respeito ao outfit, $38(17 \%)$ crianças apresentaram desajuste, das quais $18(8 \%)$ desajustaram moderadamente e $20(9 \%)$ mostraram desajuste alto. Conforme os critérios adotados, os desajustes moderados não são preocupantes. Os valores apresentados na Tabela 1 são considerados bons parâmetros psicométricos, salvo os valores extremos de infit e outfit. Seguindo o estudo é apresentada a Tabela 2 com o resumo dos parâmetros dos itens.

Observa-se na Tabela 2 que a fidedignidade dos itens, indicada pelo Índice de Fidedignidade dos Itens (Item Reliability Index) foi muito elevada. A média da pontuação total recebida pelos itens (número médio de crianças que acertaram os itens) foi de 162,8 $(\mathrm{DP}=43,2)$, com valores mínimos e máximos de $22 \mathrm{e}$ 214 , respectivamente. A média da dificuldade dos itens 
TABELA 1

Resumo dos parâmetros das crianças

\begin{tabular}{lcccccc}
\hline & Pontuação total & Medida Rasch & Erro de medida & Infit & Outfit & Valor \\
\hline Média (DP) & $84(23,7)$ & $1,74(1,79)$ & $0,33(0,13)$ & $0,98(0,18)$ & $1,13(1,01)$ & \\
Máximo & 113 & 6,18 & 1,04 & 1,62 & 9,90 & - \\
Mínimo & 1 & $-5,62$ & 0,22 & 0,61 & 0,04 & - \\
Reliability & - & - & - & - & - & 0,96 \\
Alfa de Cronbach & - & - & - & - & - & 0,98 \\
\hline
\end{tabular}

TABELA 2

Resumo dos parâmetros dos itens

\begin{tabular}{lcccccc}
\hline & $\begin{array}{c}\text { Pontuação } \\
\text { total }\end{array}$ & Medida Rasch & $\begin{array}{c}\text { Erro de } \\
\text { medida }\end{array}$ & Infit & Outfit & Valor \\
\hline Média (DP) & $162,8(43,2)$ & $0,0(1,58)$ & $0,23(0,06)$ & $0,98(0,20)$ & $1,10(1,03)$ & - \\
Máximo & 214 & 4,83 & 0,48 & 1,59 & 9,90 & - \\
Mínimo & 22 & $-3,37$ & 0,16 & 0,68 & 0,17 & - \\
Reliability & - & - & - & - & - & 0,98 \\
\hline
\end{tabular}

medida pelo modelo Rasch foi convencionalmente estabelecida como zero e o desvio padrão foi 1,58 . $\mathrm{O}$ item mais fácil obteve medida de $-3,37$ e o mais difícil de 4,83. O erro de medida médio dos itens foi $0,23(\mathrm{DP}=0,06)$, com erro mínimo de 0,16 e máximo 0,48 . Em relação aos indicadores de ajuste, a média do infit foi $0,98(\mathrm{DP}=0,20)$, com valor mínimo de $0,68 \mathrm{e}$ máximo de 1,59. A média do outfit foi $1,10(\mathrm{DP}=1,03)$ e os valores mínimo e máximo foram respectivamente 0,17 e 9,90 .

Novamente, apesar da média dos indicadores ser adequada, há valores extremos preocupantes. Para averiguar se muitos itens apresentaram desajustes moderados ou severos, foram calculadas as porcentagens de desajuste. Em relação ao infit, do total de 114 itens apenas $2(1,17 \%)$ apresentaram infit superior a 1,50 e nenhum apresentou infit superior a 2. Em relação ao outfit $16(14 \%)$ itens apresentaram desajuste, dos quais $7(6 \%)$ foram desajustes moderados e $9(8 \%)$ severos. Posteriormente, serão indicados os itens que desajustaram.

A Figura 1 mostra o mapa do construto da escrita. As palavras que aparecem mais de uma vez são seguidas das letras a, b, c para indicar a ordem em que apareceram. A Figura 1 também indica com asteriscos os itens que apresentaram valores de infit e outfit superiores a 1,50 e outfit superiores a 2,0. Valores de infit e outfit superiores a 1,50 são representados por um e dois asteriscos, respectivamente. Outfit superiores a 2,0 são indicados por três asteriscos.
Ao lado esquerdo do mapa são representados os participantes da pesquisa. Ao lado direito, as palavras do ditado. As palavras localizadas na parte superior do mapa são as mais difíceis do ditado. As que estão mais abaixo são mais fáceis. Por exemplo, Cássio foi a palavra mais difícil do ditado (nível de dificuldade de 4,83 logits). As palavras Márcio, necessário, Mário, mercúrio, difícil, chácara, dona, entre outras foram também muito difíceis.

As palavras próximas do nível de dificuldade zero são de dificuldade média, como por exemplo, as palavras colocou, mas, foi, seus, estava, muitas, achou, as, ele, entre outras. Finalmente, palavras como tenho, animais, alegre, não, tarde, para, bola, entre outras, foram muito fáceis para as crianças, com níveis de dificuldade que variaram entre $-0,74$ e $-1,46$ logits.

Além disso, na Figura 1 também são indicadas as palavras que produziram desajustes superiores a 1,50. Em relação ao infit (representadas com um asterisco), as palavras Mário e mau apresentaram desajustes moderados de 1,52 de 1,59, respectivamente. Em relação ao outfit, as palavras que apresentaram desajuste moderado foram no $(1,55)$, na $(2,00)$, e_a $(1,82)$, mercúrio $(1,69)$, iam $(1,75)$, não $(1,52)$ e estava $(1,64)$. As palavras que apresentaram desajuste de outfit severo foram Mário $(9,90)$, mau $(2,56)$, sobre $(2,55)$, chácara $(3,24)$, Dona $(4,48)$, Vanda $(2,27)$, e $(2,16)$, Márcio $(2,25)$ e, finalmente, a palavra sai $(2,01)$. 


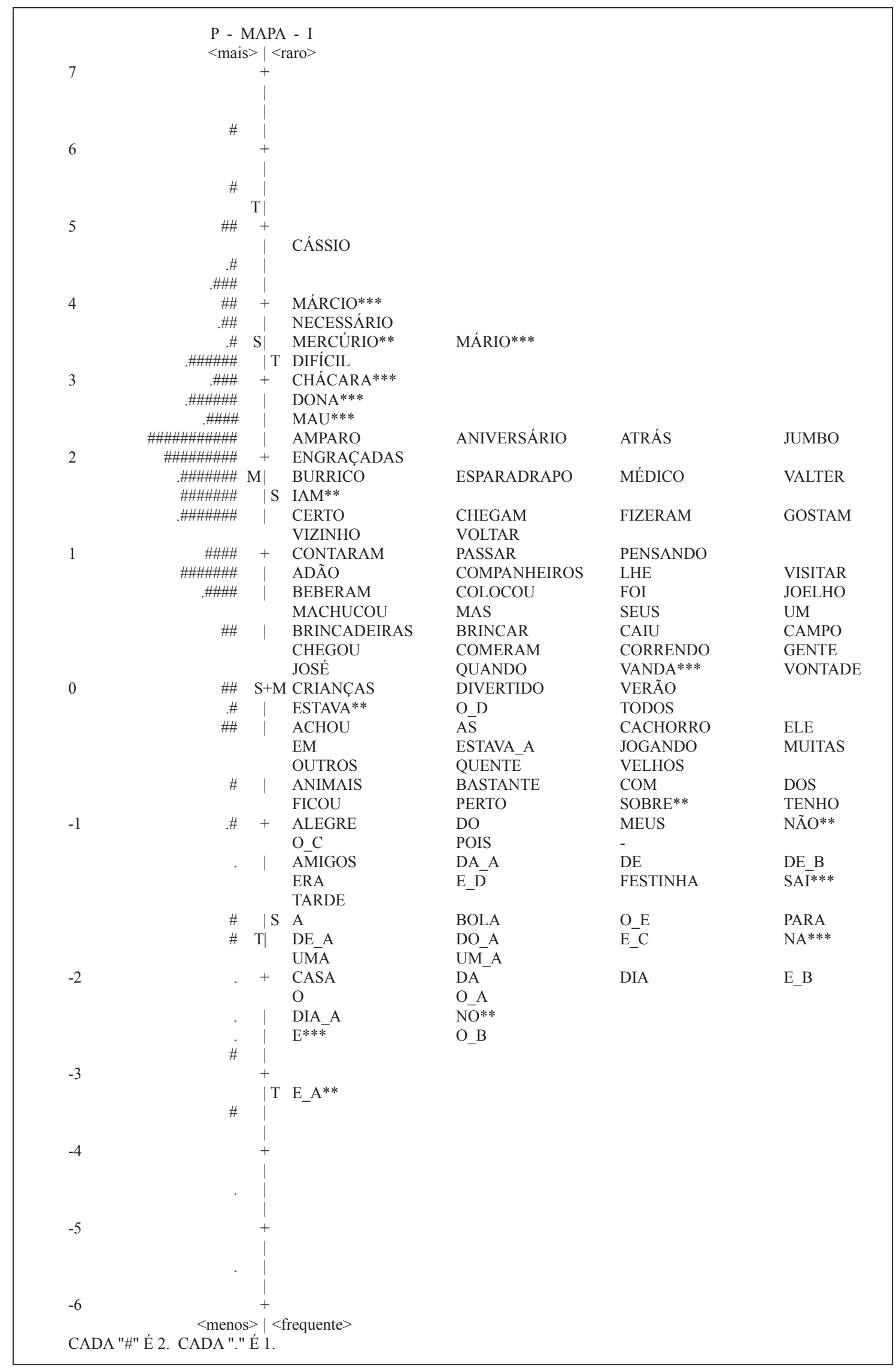

* Infit superior a 1,50;** Outfit superior a 1,50;*** Oufit superior a 2,0.

Figura 1. Mapa do construto para a escrita 


\section{DISCUSSÃO}

O objetivo deste estudo foi identificar as palavras com maior dificuldade de escrita com base na análise pelo modelo de Rasch. Em relação aos parâmetros das crianças, o infit indicou que, de forma geral, elas responderam de acordo com o esperado, pois não houve nenhum desajuste severo. Apesar do valor aberrante do desajuste observado na pontuação máxima do outfit, os resultados indicaram que a maioria das crianças respondeu conforme a expectativa do modelo de Rasch, quer dizer, acertaram a escrita das palavras de acordo com o seu nível de habilidade e o nível de dificuldade dos itens (Linacre, 2002). A quantidade de crianças que não respondeu de acordo com o esperado devido ao outfit não é preocupante, pois é inferior a $15 \%$. Além disso, o desajuste do outfit é mais sensível às respostas anômalas e, por isso, não é tão importante quanto o desajuste do infit. Os índices de precisão das crianças foram muito altos e indicam que as estimações de suas habilidades são confiáveis e que, em aplicações futuras, a maioria das crianças obteria estimativas muito parecidas.

Em relação ao ajuste dos itens, os valores médios dos indicadores de ajuste foram adequados, considerando os critérios de Linacre (2002). Não houve desajuste severo em relação ao infit, o que indica que os itens foram respondidos segundo a expectativa do modelo de Rasch, ou seja, itens difíceis foram respondidos corretamente por crianças com melhor desempenho em escrita e itens mais fáceis foram respondidos corretamente por crianças menos habilidosas ou em estágios iniciais da aquisição da escrita (Linacre, 2002).

Os itens que mais desajustaram foram principalmente itens difíceis, por isso entende-se que crianças com níveis de habilidade em escrita mais baixos escreveram corretamente essas palavras, quando, na verdade, o modelo previu que elas deveriam errar. No caso das palavras fáceis que desajustaram em relação ao outfit, entende-se que as crianças mais habilidosas as escreveram incorretamente. Apesar de não terem sido realizadas análises de comparação da habilidade em escrita entre crianças dos diferentes anos escolares avaliados, é esperado que as crianças em fases mais iniciais da alfabetização apresentem habilidade inferior, já que ainda não aprenderam ou consolidaram algumas normas linguísticas, como o uso das letras maiúsculas ou a acentuação. Assim, espera-se que crianças no início da alfabetização errem mais e, principalmente as palavras com complicações linguísticas apresentadas pelo ADAPE, em comparação com crianças em anos escolares mais avançados. No entanto, as crianças em idades iniciais podem aprender a escrever determinadas palavras ou algumas regras ortográficas por experiências que não sejam restritas à sala de aula. Quanto mais contato as crianças têm com a leitura, melhor elas escrevem (Berninger, et al., 2002) e isso pode ter influenciado as respostas corretas dessas crianças, visto que as crianças abordadas neste estudo são de escola privada. Da mesma forma, algumas crianças em séries mais avançadas poderiam escrever incorretamente as palavras mais fáceis ou que não apresentam as arbitrariedades linguísticas, por distração ou desconhecimento de significado (sintaxe).

Essas interpretações dos desajustes da escrita das crianças no ADAPE também sugerem que investigações a respeito das dificuldades de escrita devam abordar e relacionar diferenças entre contextos de aprendizagem, metodologias de ensino e condições sociais dos alunos, a fim de aprofundar explicações sobre a aquisição da escrita. Esses resultados podem indicar a instabilidade dos processos de alfabetização, à medida que as crianças cometem erros não esperados ou demonstram bom desempenho de escrita nas séries iniciais da escolarização. Assim, aparentemente o desajuste de alguns itens não deve ser considerado problemático, pois reflete parte do processo de alfabetização. Além disso, destaca-se que menos de $10 \%$ dos itens desajustou severamente no outfit. Como já foi mencionado, esse desajuste e essa porcentagem não são preocupantes.

Ainda em relação aos itens, o indicador de precisão foi muito alto. Isso indica que os valores de suas dificuldades estimadas são confiáveis e se manteriam no futuro. Além disso, destaca-se o amplo intervalo de níveis de dificuldade apresentado pelos itens do ditado, o que indica que o ADAPE é capaz de avaliar crianças em diferentes etapas da alfabetização, desde crianças no inicio da aquisição da escrita até crianças em estágios mais avançados. Essa variação da dificuldade se deve à constituição do ditado, que inclui palavras com diferentes dificuldades linguísticas previstas e palavras sem tantas complicações para a criança (Sisto, 2001).

Ainda, quando há alguns itens localizados dentro do mesmo intervalo no mapa do construto, a medição da habilidade dos participantes que estão nessa mesma região é mais precisa e é acompanhada por menos erros. Por outro lado, possuir uma grande quantidade de itens que medem o mesmo intervalo de habilidade pode ser redundante, pois uma menor quantidade poderia ser suficiente para uma avaliação precisa. Nesse sentido, deve-se tomar decisões sobre exclusão de itens redundantes. Essa decisão é mais complicada no ADAPE, pois se trata de um ditado de um texto composto por diversas orações. A exclusão de palavras 
pode invalidar algumas frases, provocar a perda de sentido das mesmas. Por isso, essa questão deve ser considerada com cautela e ainda se possui evidências suficientes da necessidade de exclusão de palavras.

Além disso, considera-se importante a exploração dessas dificuldades e identificação das dificuldades da composição das palavras, atendendo os objetivos específicos deste estudo. Para esta análise foi considerada a categorização de erros realizada por Caliatto e Martinelli (2005).

Com base nas medidas de Rasch, as palavras Cássio, Márcio e necessário representaram as maiores dificuldades de escrita do estudo. Compreende-se com base nos estudos de categorias de erros levantados na literatura (Caliatto \& Martinelli, 2005; Sisto, 2001) que essas palavras apresentam três ocorrências de dificuldades da língua: o emprego de consoante (letra c) e dígrafo (ss), o uso adequado da acentuação e o emprego da letra maiúscula. As relações entre sons e letras podem ocorrer de forma que mais de uma letra ("c" e "ss") representam o mesmo fonema /s/ em uma mesma posição. Neste caso, o emprego correto ou a escolha do grafema a ser empregado depende do conhecimento do aluno das regras contextuais da ortografia e do emprego do dígrafo "ss" entre vogais.

Outra dificuldade comum e expressa na escrita destas palavras com grande quantidade de erros é o uso da acentuação. O emprego correto do acento decorre dos alunos terem aprendido que as sílabas que recebem a acentuação são aquelas chamadas sílabas tônicas e, além disso, dependem do conhecimento das regras de acentuação, ou seja, mais um grupo de regras que também deve ser incorporada pelo estudante durante o processo escolar, para aquisição da língua escrita. Por fim, as palavras analisadas também podem ter sido escritas com erro se os estudantes deixaram de empregar a letra maiúscula nos nomes próprios: "Cássio e Márcio", desconhecendo ou não empregando esta norma.

$\mathrm{Na}$ ordem das palavras que obtiveram menores índices de acertos por parte dos participantes, duas palavras também podem ser analisadas em particular: Mário e mercúrio. A explicação encontrada para o acometimento de erro na escrita destas palavras é o emprego da consoante "r", devido à particularidade de que a letra " $r$ " tem para diferentes tipos de som ou possibilita a pronuncia de diferentes sons. $\mathrm{Na}$ escrita inicial de uma palavra incide o som grave e entre vogais quando é duplicada como em "rato e carro". Porém, quando o "r" está entre as vogais deve ser lida com som brando, o que causa dificuldade ao escritor que não emprega as regras contextuais necessárias neste caso. As regras de cotexto da escrita indicam que o local da letra na composição da palavra determina seu uso correto. Outra dificuldade que apresentaram essas palavras foi novamente o emprego do acento. Os outros casos de palavras com menos quantidade de acertos neste estudo e que podem ser exploradas para explicação das dificuldades da língua escrita, foram dispostas em grupos conforme apresentadas a seguir.

Palavras com acento agudo foram muito recorrentes entre as palavras mais difíceis como dificil, chácara, atrás e aniversário. Poucos estudos se propuseram a análise da aquisição deste domínio e versam sobre estratégias linguísticas fonológicas (estrutura silábica, contorno entonacional, ritmo) e morfológicas (ver Santos, 2001 para um levantamento). Neste contexto, o que se conjectura é que a fala, o domínio da escrita e as normas da língua se intercalam causando dificuldade para o domínio e uso da acentuação das palavras, podendo-se considerar comum os erros dessa categoria entre os escritores imaturos.

Palavras que necessitam do emprego de dígrafos como em chácara, burrico, vizinho ou sílabas complexas, como no caso das palavras: aniversário, engraçadas, esparadrapo, certo são particularmente difíceis aos escritores menos experientes ou das séries iniciais. Isso foi apontado pelos estudos que categorizaram os erros mais frequentes e próprios da língua portuguesa, abordando aspectos linguísticos e gramaticais em termos fonológicos, morfológicos e sintáticos (Bortoni-Ricardo, 2004; Cagliari, 2006; Zorzi \& Ciasca, 2009), assegurando que os alunos que têm acesso limitado à norma ortográfica sofrerão maior inferência das regras fonológicas e morfológicas de seu dialeto na escrita. Nestes casos os erros podem ser previstos conhecendo-se as características do dialeto em questão e antecipando-se o ensino da norma culta.

Buscando explicar o acometimento de erros e as dificuldades encontradas em dígrafos e sílabas complexas em escritas com erro, neste estudo podese considerar a perspectiva que os erros foram cometidos devido às características dos dígrafos representarem diferentes sons como $/ \mathrm{r} /$, $/ \mathrm{x} /$ que podem ser representados por letras diferentes, como ocorre nas palavras "xácara" para chácara; "burico" em vez de burrico (Caliatto \& Martinelli, 2005).

Outros estudos consideram ainda que os alunos podem cometer erros de escrita ao relacionarem novas palavras com outras que já conhecem. Nesse sentido, Sisto (2001) e Morais (2007) verificaram que, ao perceberem a falta de relação biunívoca entre fala e escrita, as crianças empregam generalizações de grafias que julgam corretas como em "aniverssário" em vez de aniversário; "esparadlapo" esparadrapo. Segundo os estudos, a tipologia de erros pode demonstrar 
características ortográficas problemáticas, ajudando a priorizar conteúdos ortográficos orientados para as reais necessidades dos alunos. Ainda neste estudo encontraram-se palavras com escritas inapropriadas em amparo, iam, fizeram, gostam, chegam, jumbo, mau, voltar, Tratou-se de explorar que o emprego das sílabas que representam o som nasal constitui uma grande fonte de dificuldade para escrever, porque existem no português escrito, vários modos de representá-los (Morais, 2007). Esta dificuldade em definir o som nasal pode provocar erros de trocas, omissões e acréscimo de letras em várias posições na palavra. Zorzi e Ciasca (2009) destaca o problema da nasalização das sílabas como um problema de escrita apoiado na oralidade e de ordem de representação de um mesmo som por letras diferentes, como as escritas "ião" para iam, "junbo" em lugar de Jumbo.

\section{CONSIDERAÇÕES FINAIS}

De forma geral, os parâmetros psicométricos dos participantes e dos itens foram bons indicadores das respostas das crianças e das estimativas de suas medições. Os indicadores de fidedignidade das respostas dos participantes e dos níveis de dificuldade dos itens foram muito altos, o que sugere que a localização e ordem de suas habilidades e dificuldades são precisas. $\mathrm{O}$ alto desajuste relacionado com o outfit, apesar de não ser preocupante para a qualidade do ditado, poderia ser investigado e explicado mais detalhadamente em estudos futuros.

Constatou-se que há uma variabilidade considerável da dificuldade dos itens, no ditado ADAPE, o que é muito importante para avaliar crianças com distintos níveis de habilidade ou em diferentes momentos do processo de alfabetização. Quer dizer, o ditado contêm palavras mais fáceis adequadas para avaliar crianças mais novas ou com dificuldades de aquisição da escrita, assim como palavras mais difíceis que são mais adequadas para mensurar a escrita de crianças em estágios mais avançados da aprendizagem. Com isso, realizou-se uma especulação dos motivos pelos quais algumas palavras são mais difíceis que outras.

Não foi objeto deste estudo analisar os tipos de erros dos alunos, mas, explorar a dificuldade das palavras do ADAPE. Sugere-se que outras investigações sejam realizadas de forma pormenorizada para explicar ou compreender melhor as dificuldades das palavras ou ainda para uma análise dos erros de escrita por ano escolar. Neste contexto aponta-se as limitações deste estudo à medida que sua amostra foi restrita a apenas uma escola do sistema de ensino privado. Ainda, é necessária a ampliação das aplicações em escolas públicas e particulares.

Importante ressaltar as implicações pedagógicas deste estudo que se referem à dar atenção às principais possibilidades de erros encontradas nas palavras com dígrafos e sílabas complexas, incluindo o emprego das sílabas que representam o som nasal, além do uso de acentos. Entende-se que essas características estruturais das palavras as tornam mais difíceis que outras. As dificuldades recorrentes da língua, representadas pelas palavras mais difíceis do ADAPE, tendem a diminuir a medida que os estudantes percebem as diferentes estruturas silábicas (Sisto, 2001), o que provavelmente ocorrerá na progressão dos anos escolares.

Contudo, algumas intervenções devem ser feitas quando se trata de dificuldades passíveis de prevenção a partir do trabalho de diferenciação entre erros. A primeira possibilidade está relacionada ao reconhecimento de escritas regulares contextuais, quando o contexto da palavra define qual letra terá de ser utilizada de acordo com uma regra, como é o caso dos "rr" e "ss". Por outro lado, as relações múltiplas definidas entre letras representadas por vários sons e um som representado por vários grafemas (Lemle, 2004) são as arbitrariedades ou irregularidades da língua e esse aprendizado depende da memorização das regras ortográficas. Concebe-se que é necessário que o professor conheça bem o funcionamento da ortografia e da língua para interferir nas dificuldades de escrita de seus alunos e promover a aprendizagem. Além disso, deve reconhecer que o erro apresentado pelo aluno é como um guia de planejamento para intervenções.

\section{REFERÊNCIAS}

Bortoni-Ricardo, S. M. (2004). Educação em língua materna: a sociolingüística na sala de aula. São Paulo: Parábola.

Bublitz, G. K. (2010). A consciência sintática de crianças que ingressam aos 6 anos no Ensino Fundamental. Letras de Hoje, 45(3), 92-97.

Cagliari, L. C. (2006). Alfabetização e Linguística (10ª ed). São Paulo: Scipione.

Caliatto, S. G. (2005). Avaliação da escrita em jovens e adultos (Dissertação de mestrado). Faculdade de Educação, Universidade Estadual de Campinas, Campinas, SP.

Campos, A. M. G., Pinheiro, L. R., \& Guimarães, S. R. K. (2012). A consciência fonológica, a consciência lexical e o padrão de leitura de alunos com dislexia do desenvolvimento. Revista Psicopedagogia, 29(89), 194-207.

Embretson, S. E., \& Hershberger, S. L. (1999). The new rules of measurement: What every psychologist and educator should know. New Jersey: Lawrence Erlbaum.

Kessler, B., \& Treiman, R. (2013). Sistemas de escrita e desenvolvimento da ortografia. In M. J. Snowling, \& C. Hulme (Orgs.). A ciência da leitura (pp. 138-152). Porto Alegre: Penso. 
Linacre J. M., (2002).What do Infit and Outfit, Mean-Squared and Standardized mean? Rasch Measurement Transactions, 16(2), 878. Disponível em http://209.238.26.90/rmt/rmt82a.htm [Acesso em outubro 2013].

Linacre, J. M. (2009). A user's guide to Winsteps, \& Ministeps: Rasch Model Computers Programs. Winsteps.com, Chicago, IL Disponível em http://www.winsteps.com/winman/index. htm?copyright.htm [Acesso em outubro 2013].

Manzano, J. L. G., Sanz, M. T., \& Chocano, A. J. D. (2008). Fundamentos para la intervención en el aprendizaje de la ortografia. Madrid, Espanha: Editorial CEPE.

Morais, A. G. (2007). Ortografia: Ensinar e aprender (4ª ed.). São Paulo: Ática.

Mota, M., Besseb, A. S., Diasc, J., Paivac, N., Mansur-Lisboac, S., \& Silva, D. A. (2011). O desenvolvimento da consciência morfológica nos estágios iniciais da alfabetização. Psicologia Reflexão e Crítica, 24(1), Disponível em http://www.scielo.br/scielo. php?script=Sc_arttext\&pid=S0102-79722011000100017\& lng=en\&nrm=iso [Acesso em 28 nov. 2013].

Paolucci, J. F., \& Ávila, C. R. B. (2009). Competência ortográfica e metafonológica: influências e correlações na leitura e escrita de escolares da 4⿳亠丷a série. Revista da Sociedade Brasileira de Fonoaudiologia, 14 (1), 48-55.

Rasch, G. (1960). Probabilistic models for some intelligence and attainment tests. Copenhagen: Danmarks Paedagogiske Institut.

Santos, R. S. (2001). Aquisição do acento primário no português brasileiro (Tese de doutorado). Instituto de Estudos da Linguagem, Universidade Estadual de Campinas, Campinas, SP.
Sisto, F. F. (2001). Dificuldades na aprendizagem em escrita: um instrumento de avaliação (ADAPE). In F. F. Sisto, E. Boruchovitch, L. D. T. Fini, R. P. Brenelli, \& S. C. Martinelli (Orgs.). Dificuldades de aprendizagem no contexto psicopedagógico (pp. 190-213). Petrópolis: Vozes.

Sisto, F., \& Martinelli, S. C. (2008). O papel das relações sociais na compreensão do fracasso escolar e das dificuldades de aprendizagem. In F. F. Sisto, \& S. C. Martinelli, (Orgs.). Afetividade e dificuldades de aprendizagem: uma abordagem psicopedagógica (pp. 13-30). São Paulo: Vetor.

Urquijo, S. (2009). Aprendizaje de la lectura. Diferencias entre escuelas de gestión pública y de gestión privada. Evaluar, 9, 19-34.

Zorzi J. L., \& Ciasca S. M. (2009). Análise de erros ortográficos em diferentes problemas de aprendizagem. Revista CEFAC, 11(3), 406-416.

\section{Autores:}

Susana Gakyia Caliatto - Doutora, Universidade do Vale do Sapucaí.

Débora Cecílio Fernandes - Doutora, Universidade do Vale do Sapucaí.

Endereço para correspondência:

Susana Gakyia Caliatto

Universidade do Vale do Sapucaí

Pouso Alegre, MG, Brasil

E-mail: caliatto@uol.com.br

Recebido em: 28.03.2014

Aceito em: 03.06.2014 